\title{
Research on Cooperative Mechanism among APSN to Improve the International Competitiveness of Ningbo Port
}

\author{
Yujun Duan ${ }^{1, a}$, Lili Ma ${ }^{2, b}$ \\ (Ningbo Dahongying University,Ningbo 315175) \\ ${ }^{1 \sim 2}$ No.899. Xueyuan Road, Yinzhou District, Ningbo City,Zhejiang Prov, China \\ a 38213912@qq.com, ${ }^{b}$ 78858361@qq.com
}

Keywords: cooperative mechanism, ASPN, Ningbo port

Abstract. Port development has benefited from the development of international trade and shipping. The pattern of international trade and the change of shipping also affect the adjustment of port layout. Nowadays, regional economic integration as new trade pattern which promote port constantly improve on the function and operation. The development of the large scale of the ship, to some extent, restricted the growth of the number of service loops. But on the other hand, service quality improving is required. Therefore, the port and its economic circle cooperation is the best way to fit new trade pattern. This paper is to research on cooperative mechanism among APSN for Ningbo port.

\section{Introduction}

This article aims at establishing long-term cooperative mechanisms, which is the key and difficult point of strengthening regional port cooperation to improve the international competitiveness of Ningbo port at government level and non-governmental level. Especially, market convergence and communication mechanisms would be set up among the government, industry association and enterprise, which focus on strengthening the communication between the local government industrial policy, eliminating the barriers to entry and discriminatory policies, and promoting the further opening of the ports and dockings. At last, the ports in APSN (APEC Port Service Network) could achieve dislocation development, cooperation and win-win. This article would be finished with some concluding remarks.

\section{Premise}

This section provides an overview of the importance of improving international competition for Ningbo port, the cooperative demands of ports within ASPN, the relationships between cooperation planning and long-term cooperative mechanism.

The rapid development of Ningbo Port benefited from its unique natural conditions with a hinterland of the economically developed. But it is lack of integrated service system. And the level of development of port can not make the balance of resource in the shore. The competitions from other ports always exist, such as Shanghai port. Also there are too many ports in the Asia and Pacific regions. APSN is a good chance for Ningbo port to cooperate with the members to improve its international competitiveness.

According to APSN research, the GDP growth in developed economies has recovered to over $2 \%$, and the GDP growth of emerging markets and developing economies has weakened to around 5\%. The proportion of emerging markets and developing economies is increasing in world output. The figure also showed strong demand growth will not continue while global trade show a steady growth trend. By using Liner Shipping Bilateral Connectivity Index (LSBCI) to reflect specifically the liner shipping connectivity between pairs of countries which shows $67 \%$ of the countries moved up in terms of LSBCI performance. A deeper analysis shows that the top 50 LSBCIs are found on connections between maximum 15 countries and that the top 250 LSBCIs are found on connections between maximum 40 countries. These findings mean ports cooperation and partnerships would be established in APEC region, and ports and relative industry need policy to 
incent.

As ASPN stated, the mission of ASPN is to promote the development of APEC port industry by fostering a more cohesive and cooperative partnership among APEC port and port-related industries. This basic mission needs to encourage the members build the capacity and share information. Also, the members among ASPN need to understand each other. APSN provides a platform for APSN members to conduct economic and technical cooperation, exchange management expertise and experience, carry out personnel training, enhance technology transfer and promote trade and investment.

\section{Implementation Guarantee}

As infrastructure investment, international cooperation and partnerships and policy incentives are three main factors which affect the implementation of cooperation, this section would like to describe the three implementation guarantees begin with common challenges.

Common Challenges. Firstly, Most of APEC members have common features that they need connectivity. Not only the physical connectivity, but also institutional and people-to-people. Secondly, they have different economic conditions and potential. Secondly, transport costs of the members are relatively expensive because of long distance between ports, imbalance in economy activities among members, varying port facilities, disconnected transport network, lacking of stable and efficient transport service for cargos and passengers and lack of data and statistics. Thirdly, basic operating function such like berthing availability, handling productivity and dock capability are required to upgrade. Gantry crane deployed per vessel cannot be increased in direct proportion to ship size due to ship length is not increase with TEU intake. Gantry crane are higher and have longer outreaches. Trolley has to travel further per cycle between the quay and the ship's hold. More transshipment cargo to connect feeder, train and truck. Fourthly, the development of the large scale of the ship, to some extent, restricted the growth of the number of service loops. It reduced service frequency while greater volume peak for big ships. Big ships cascade big berth and dock capacity, high productivity, which also leading to segmentation of terminal that handle mega vessels exclusive and terminal unable to accommodate the larger ships are falling out.

Implementation Guarantee. Firstly, port community system (PCS) could be established. PCS could reduce inefficiencies in port business processes and integrate and achieve compliance with national and International Regulations. It is formed by the community, for the community and are, in general, members of APSN. PCS could facilitate the smooth flow of electronic data. Electronic facilitation of goods through improved data exchange will mean fewer delays in cargo movements. Also it can simplify the Administrative processes such as Customs. Secondly, form consensus and understanding between stakeholders about that sharing information can activate port, shipping and logistics business. They could set common objectives and goals for pursuing information sharing services and indentify needs from user sides before building information sharing systems for all partners.

\section{Cooperation Mechanism}

Based on the previous analysis, taking full advantages of different funds of port cooperation, concentrating on the port cooperation with the countries among APSN, exploring port international cooperation model, this section would establishing normalized port international cooperative mechanism in the fields of the construction and cooperation of shipping and ports, maritime search and rescue, navigation safety, marine environmental protection, etc..

Mechanism. We divided cooperative mechanism into two types because cooperation would happen between two ports or among three or more ports. One is bilateral cooperation, which carry out multilevel and multi-channel communication and negotiation. Governments or non-government parties can propel the signing of memorandum of cooperation or cooperative planning and set a bilateral port cooperation example. Another is multilateral cooperation, which take advantage of the existing port international cooperative organizations, technology, manpower and mechanisms to 
enhance the communication and port-related project cooperation.

Mechanism of International cooperation of maritime transportation and port interconnection. They include lanes connection between ports, enterprise investment cooperation, port and shipping personnel exchange and training, cooperation in the standards and technical specifications of maritime transportation and ports, port and shipping and logistics information sharing. Information Network Organization could be established as NEAL-NET which formed in 2010 to promote regional land-ocean transport cooperation comprehensively and accelerate the expansion of network service.

Mechanism of port search and rescue international cooperation. It includes search and rescue action cooperation, personnel exchange and training cooperation, search and rescue information and data resources sharing cooperation, technical project cooperation, search and rescue capacity building cooperation.

Mechanism of marine environmental protection international cooperation. It concludes marine pollution emergency disposal cooperation, marine pollution prevention information and data resources sharing cooperation, marine pollution prevention personnel exchange and training cooperation, marine pollution prevention technical project international cooperation and capability cooperation.

Mechanism of marine navigation safety international cooperation. It concludes maritime security and anti-terrorism action cooperation, marine navigation safety information and data resources sharing cooperation, maritime personnel exchange and training cooperation, marine navigation safety technical project international cooperation and capability cooperation, and maritime safety supervision capacity building cooperation.

Mechanism of marine salvage international cooperation. It concludes humanitarian and social welfare maritime salvage international cooperation and commercial salvage international cooperation.

Suggestions. Firstly, promote comprehensive cooperation among ports. Strengthen the shipping line linkage and strengthen Trade Agreement Innovation. Secondly, advance seamless connection between shipping and port. The interface facilitation between shipping and port and high resource sharing mechanism should be realized. Also, dynamic interface between shipping and port should be built. Thirdly, Build smooth linkage between port and hinterland. This would enhance the harmonious relationship between port cities. To improve the international competitiveness for Ningbo port, a comprehensive transport system should be established. Information sharing along the whole supply chain would be realized. At last, promote sustainable development of ports. Energy saving and emission reduction is required nowadays. Therefore, we should encourage innovation to improve the green development concept and share best practices.

\section{Summary}

Ningbo port carries out maritime multi-field and multilevel international cooperation with the countries among APSN. Different countries among APSN can participate in the construction of Maritime Silk Road activity, build friendly partnership, share the achievements of maritime interconnection and make positive contributions to the economic rapid development, social harmony and happiness of people. Port cooperation may include multiple sister port agreements, revenue generation, innovation, cost controls, counter weight to global port operator, global talents, big data, Internet of things, etc.

\section{Acknowledgements}

This work was financially supported by the Ningbo Science and Technology Bureau (2015A10075, 2014A10077), Zhejiang Academy of Social Sciences (15JDLG04YB) and Ningbo Academy of Social Sciences (G16-ZC08). This work was also financially supported by Ningbo Modern 
Logistics Planning Institute (Ningbo Traffic Development Research Center) for project "Study on the logistics system of cross-border e-commerce in Ningbo”.

\section{References}

[1] Chambers, S. New international investments leads to best year to date for China port, Lloyds List, 16 March, 2005.

[2] Dong YANG. Promote Ports Connectivity in APEC Region [EB/OL]. 11 ${ }^{\text {th }}$ Nov. 2015, http://www.apecpsn.org/index.php?s=/Documents/documentList/cateId/3/sid/31/clickType/pres entation. 25th June, 2016.

[3] Alexandra Stepanova. Comparative analysis of cooperation mechanisms between power authorities and civil society institutions: by the cases of Russia and Great Britain [J]. Int Rev Public Nonprofit Mark, 2010 (7): 97-99.

[4] Xiwen Bai and Jasmine Siu Lee Lam. Dynamic regional port cluster development: case of the ports across Taiwan Strait [J]. GeoJournal, 2015(80): 619-636.

[5] De Langen, P. W. Governance in seaport clusters.Maritime Economics and Logistics [J]. 2004, 6 (2): 141-156.

[6] Mauricio Salgado, José A. Noguera and Francisco J. Miguel. Modelling Cooperation Mechanisms: Some Conceptual Issues [J]. J Archaeol Method Theory, 2014 (21): 325-342. 